\title{
Inhibition of Vesicular Glutamate Uptake by Rose Bengal-Related Compounds: Structure-Activity Relationship
}

\author{
David G. Bole, ${ }^{1}$ and Tetsufumi Ueda ${ }^{1-4}$
}

(Accepted February 1, 2005)

\begin{abstract}
Synaptic vesicular accumulation of glutamate is a vital initial step in glutamate transmission. We have previously shown that Rose Bengal, a polyhalogenated fluorescein analog, is a potent inhibitor of glutamate uptake into synaptic vesicles. Here, we report the structural features of Rose Bengal required for this inhibition. Various Rose Bengal-related compounds, with systematic structural variations, were tested. Results indicate that the four iodo groups and the phenyl group attached to the xanthene moiety are critical for potent inhibitory activity. Replacement of these groups with two iodo groups and an alkyl group, respectively, results in substantial reduction in potency. Of further interest in creating high potency is the critical nature of the oxygen atom which links the two benzene rings of xanthene. Thus, the phenyl group and multiple iodo groups, as well as the bridging oxygen of xanthene, are crucial elements of Rose Bengal required for its potent inhibitory action.
\end{abstract}

KEY WORDS: Rose Bengal; erythrosin; vesicular uptake; Glutamate.

\section{INTRODUCTION}

Glutamate (Glu) is widely accepted as the major excitatory neurotransmitter in the vertebrate central nervous system, and Glu-mediated neurotransmission plays a key role in learning and memory formation, as well as basic neural communication. Aberrant Glu transmission is known to lead to various pathological conditions in the central nervous system. In the presynaptic terminal of neurons Glu is transported into synaptic vesicles prior to exocytotic release. The energy-dependent vesicular Glu uptake system plays a vital role in the initial step of Glu

\footnotetext{
${ }^{1}$ Mental Health Research Institute, University of Michigan Medical School, Ann Arbor, Michigan, USA.

${ }^{2}$ Department of Pharmacology, University of Michigan Medical School, Ann Arbor, Michigan, USA.

${ }^{3}$ Department of Psychiatry, University of Michigan Medical School, Ann Arbor, Michigan, USA.

${ }^{4}$ Address reprint requests to: T. Ueda, MHRI, University of Michigan Medical School, MSRB II, C570, 1150 W. Medical Center Dr., Ann Arbor, MI, 48109-0669, USA. Tel: + (734)7633790; Fax: +(734)936-2690; E-mail: tueda@umich.edu
}

transmission by directing Glu into the synaptic vesicle (1-6). It is distinct from the sodium-dependent Glu uptake system present in the plasma membrane responsible for re-uptake of released Glu $(7,8)$. The ATP-dependent vesicular Glu uptake system consists of at least two functional components, v-type protonpump ATPase and Glu-specific transporters $(1,3,9$ 11). There are three isoforms of vesicular Glu transporters having differential distributions (for reviews see ref. 12). ATP hydrolysis generates an electrochemical proton gradient that serves as the driving force for translocation of Glu from the cytosol into the lumen space of synaptic vesicles in the presence of low concentrations of chloride (8-10,13-15). In view of the vesicular Glu uptake system's pivotal role in the first phase of Glu synaptic transmission, vesicular Glu transport has been considered a potential target for manipulating Glu transmission.

Vesicular Glu uptake has been shown to be inhibited by the ergot bromocriptine $(16,17)$, the Glu

Abbreviations: Glu, Glutamate; DMSO, Dimethyl sulfoxide; KRB, Krebs-Ringer buffer; DTT, dithiothreitol; RBL, Rose Bengal lactone. 
analog trans-1-aminocyclopentane-1,3-dicarboxylate $(18,19)$, the highly charged anionic dyes Trypan Blue and Chicago Blue (20), as well as an endogenous inhibitory protein factor (21). Carrigan et al. have synthesized various derivatives of quinoline-2,4dicarboxylic acid and showed that they act as competitive inhibitors of vesicular Glu uptake $(22,23)$. Most of these agents are, however, membrane-impermeant, except for bromocriptine. Recently, the polyhalogenated fluorescein derivative Rose Bengal has been found to be a potent inhibitor of Glu uptake into isolated synaptic vesicles (24). The high potency of Rose Bengal has raised the possibility that it might serve as a prototype xenobiotic regulatory agent which could alter vesicular Glu storage and Glu synaptic transmission. In an effort to identify the pharmacophore of Rose Bengal, we have here studied the structure-activity relationship of certain fluorescein derivatives in inhibiting vesicular Glu uptake.

\section{EXPERIMENTAL PROCEDURE}

Fluorescein-related test compounds listed in Table I were purchased from Sigma-Aldrich (St. Louis, MO) unless otherwise noted. Stock solutions of each compound were first prepared to a concentration of $10 \mathrm{mM}$ (DMSO) based on weight, and adjusted by dilution to $5 \mathrm{mM}$, after concentration was determined by spectrophotometry based upon the following molar extinction coefficients: $96,100 \mathrm{M}^{-1} \mathrm{~cm}^{-1}$ at $549 \mathrm{~nm}$ (Rose Bengal) in $1 \%$ $\mathrm{Na}_{2} \mathrm{CO}_{3} ; 99,400 \mathrm{M}^{-1} \mathrm{~cm}^{-1}$ at $558 \mathrm{~nm}$ (Rose Bengal lactone) in methanol; $83,100 \mathrm{M}^{-1} \mathrm{~cm}^{-1}$ at $526 \mathrm{~nm}$ (Erythrosin B) in $1 \%$ $\mathrm{Na}_{2} \mathrm{CO}_{3} ; 108,000 \mathrm{M}^{-1} \mathrm{~cm}^{-1}$ at $530 \mathrm{~nm}$ (Erythrosin B lactone) in methanol; 84,200 $\mathrm{M}^{-1} \mathrm{~cm}^{-1}$ at $538 \mathrm{~nm}$ (Erythrosin B isothiocyanate lactone) in methanol; $84,000 \mathrm{M}^{-1} \mathrm{~cm}^{-1}$ at $517 \mathrm{~nm}$ (Eosin Y) in $1 \% \mathrm{Na}_{2} \mathrm{CO}_{3} ; 107,000 \mathrm{M}^{-1} \mathrm{~cm}^{-1}$ at $523 \mathrm{~nm}$ (Eosin $\mathrm{Y}$ lactone) in methanol; 52,900 $\mathrm{M}^{-1} \mathrm{~cm}^{-1}$ at $517 \mathrm{~nm}$ (Eosin B) in $1 \% \mathrm{Na}_{2} \mathrm{CO}_{3}$; $89,609 \mathrm{M}^{-1} \mathrm{~cm}^{-1}$ at $520 \mathrm{~nm}$ (methyl Eosin) in $1 \% \mathrm{Na}_{2} \mathrm{CO}_{3}$; $270,600 \mathrm{M}^{-1} \mathrm{~cm}^{-1}$ at $533 \mathrm{~nm}$ (ethyl Eosin) in $1 \% \mathrm{Na}_{2} \mathrm{CO}_{3}$; $13,200 \mathrm{M}^{-1} \mathrm{~cm}^{-1}$ at $518 \mathrm{~nm}$ (Eosin B lactone) in $0.1 \mathrm{M} \mathrm{NaOH}$; $145,100 \mathrm{M}^{-1} \mathrm{~cm}^{-1}$ at $512 \mathrm{~nm}\left(2^{\prime}, 7^{\prime}\right.$-dichlorofluorescein lactone) in ethanol plus 1 drop of $1 \mathrm{M} \mathrm{NaOH} ; 57,300 \mathrm{M}^{-1} \mathrm{~cm}^{-1}$ at $516 \mathrm{~nm}$ (diiodofluorescein) in methanol plus 1 drop of $1 \mathrm{M} \mathrm{NaOH}$; $104,983 \mathrm{M}^{-1} \mathrm{~cm}^{-1}$ at $548 \mathrm{~nm}$ (Phloxine B) in $50 \%$ ethanol plus $1 \%$ $\mathrm{Na}_{2} \mathrm{CO}_{3} ; 24,428 \mathrm{M}^{-1} \mathrm{~cm}^{-1}$ at $518 \mathrm{~nm}$ (tetrachlorofluorescein) in methanol plus 1 drop of $1 \mathrm{M} \mathrm{NaOH}$. Methyl Rose Bengal, benzyl Rose Bengal, decarboxylated Rose Bengal, and 2,3,5,7-tetraiiodosuccinylfluorescein were the generous gift of Dr. F. AmatGuerri, Consejo Superior de Investigaciones Cientificas, Instituto de Quimica Organica General, Madrid, Spain $(25,26)$ and prepared as $5 \mathrm{mM}$ stocks; the concentration of these compounds was determined based upon weight.

\section{Preparation of Synaptic Vesicles from Rat Brain}

Frozen brains from Sprague-Dawley rats (body weight $\sim 150$ g) were purchased from Pel-Freez Biologicals (Rogers, AR)
Table I. Effect of Halogenated Fluorescein Derivatives on ATPdependent Uptake of $\left[{ }^{3} \mathrm{H}\right]$ Glu into Synaptic Vesicles

\begin{tabular}{|c|c|}
\hline Test compound & $\mathrm{IC}_{50}(\mathrm{nM})$ \\
\hline Rose Bengal lactone & $18 \pm 1.3$ \\
\hline Rose Bengal & $22 \pm 0.7$ \\
\hline Erythrosin B lactone & $30 \pm 3.0$ \\
\hline Erythrosin B & $35 \pm 11.1$ \\
\hline Methyl Rose Bengal & $44 \pm 2.6$ \\
\hline Phloxine B & $51 \pm 0.8$ \\
\hline Benzyl Rose Bengal & $65 \pm 6.8$ \\
\hline Ethyl eosin & $65 \pm 5.2$ \\
\hline Decarboxylated Rose Bengal & $68 \pm 3.5$ \\
\hline Methyl eosin & $117 \pm 16.0$ \\
\hline Eosin Y lactone & $406 \pm 40.0$ \\
\hline Erythrosin B isothiocyanate lactone & $689 \pm 66.0$ \\
\hline Eosin Y & $743 \pm 84.0$ \\
\hline Diiodofluorescein & $1,066 \pm 77.0$ \\
\hline 2,4,5,7-Tetraiodosuccinylfluorescein & $2,187 \pm 24.0$ \\
\hline Eosin B lactone & $2,445 \pm 481.0$ \\
\hline $3^{\prime}, 3^{\prime \prime}, 5^{\prime}, 5^{\prime \prime}$-Tetraiodophenolphthalein & $3,850 \pm 150.0$ \\
\hline 4,5,6,7-Tetrachlorofluorescein lactone & $15,000 \pm 984.0$ \\
\hline Pyrogallol Red & $>32,000$ \\
\hline $2^{\prime}, 7^{\prime}$-Dichlorofluorescein lactone & $>64,000$ \\
\hline
\end{tabular}

Rat brain synaptic vesicles $(10 \mu \mathrm{g})$ were pre-incubated in the absence or presence of different concentrations of each test compound for $30 \mathrm{~min}$ at $0^{\circ} \mathrm{C}$, then assayed for ATP-dependent uptake for 10 min at $30^{\circ} \mathrm{C}$, as described in 'Experimental Procedure.' An $\mathrm{IC}_{50}$ value was determined for each compound from sigmoidal doseresponse curves, an example of which is shown in Fig 2. Data points represent the mean \pm standard deviation $(n=3)$.

and stored at $-80^{\circ} \mathrm{C}$. Thirty-five frozen rat brains were thawed for $15 \mathrm{~min}$ on ice in 1.01 of $0.32 \mathrm{M}$ sucrose solution containing $4 \mathrm{mM}$ Tris- $\mathrm{HCl}$ (pH 7.4), $0.1 \mathrm{mM}$ DTT, and 6-7 brains homogenized in $170 \mathrm{ml}$ aliquots, using a $225-\mathrm{ml}$ glass Dounce homogenizer fitted with a Teflon pestle. The resulting homogenate was centrifuged at $1000 \times g_{\max }$ (Sorvall GSA rotor, $2500 \mathrm{rpm}$ ) for $10 \mathrm{~min}$, and the supernatant collected and centrifuged at $11,700 \times g_{\max }$ (Sorvall GSA rotor, $9000 \mathrm{rpm}$ ) for $20 \mathrm{~min}$. The resulting supernatant was discarded. The $\mathrm{P} 2$ synaptosomal pellets were homogenized in an equal volume of ice-cold Krebs-Ringer buffer (KRB) containing $150 \mathrm{mM} \mathrm{NaCl}, 2.4 \mathrm{mM} \mathrm{KCl}, 1.2 \mathrm{mM}$ $\mathrm{Na}_{2} \mathrm{HPO}_{4}, 1.2 \mathrm{mM} \mathrm{CaCl}, 1.2 \mathrm{mM} \mathrm{MgSO} 4,0.1 \mathrm{mM}$ DTT, and $5 \mathrm{mM}$ HEPES buffered to $\mathrm{pH} 7.4$ with Tris base. The KRBsuspended $\mathrm{P} 2$ crude synaptosomes were pelleted by centrifugation for $10 \mathrm{~min}$ at $6000 \times g_{\max }$ (Sorvall GSA rotor, 6,000 rpm). The KRB-washed P2 synaptosomal pellets were then subjected to hypotonic osmotic shock by homogenization in $360 \mathrm{ml}$ of ice-cold $6 \mathrm{mM}$ Tris, $0.1 \mathrm{mM}$ DTT, buffered to $\mathrm{pH} 8.1$ with malic acid, and allowed to stand on ice for $45 \mathrm{~min}$. After incubation at $0^{\circ} \mathrm{C}$, the ruptured synaptosomal membrane and other cellular debris were removed by centrifugation at $32,800 \times g_{\max }$ (Sorvall SS 34 rotor, $16,500 \mathrm{rpm}$ ) for $25 \mathrm{~min}$. The supernatant was centrifuged at $150,000 \times g_{\max }($ Beckman $45 \mathrm{Ti}, 35,000 \mathrm{rpm})$ for $70 \mathrm{~min}$. The resulting pellets, which contain synaptic vesicles (crude synaptic vesicle preparation), were resuspended in $0.32 \mathrm{M}$ sucrose, $1 \mathrm{mM}$ DTT, $4 \mathrm{mM}$ Tris- $\mathrm{HCl}(\mathrm{pH}$ 7.4), at a protein concentration of $2 \mathrm{mg} / \mathrm{ml}$, aliquoted into cryovials, and stored under liquid nitrogen. Typically $7-10 \mathrm{mg}$ of crude synaptic vesicles (with respect to protein) were obtained from 35 frozen rat brains. The vesicle fraction had a specific uptake activity of $1.5-3.0 \mathrm{nmol} \mathrm{Glu} / \mathrm{mg}$ protein under our standard assay conditions described below. The 
ratio of ATP-dependent to ATP-independent uptake of Glu was determined to be 83 . The crude synaptic vesicles utilized in this study were pooled from multiple preparations (140 rat brains). In some experiments, these crude vesicles were suspended in $4 \mathrm{mM}$ HEPES-Tris ( $\mathrm{pH}$ 7.4) containing $0.1 \mathrm{mM}$ DTT, and further purified by sucrose density gradient centrifugation $(24,800 \mathrm{rpm}$ for $2 \mathrm{~h}$ in a Beckman 40.1 SW Ti rotor); the gradient consisted of $3.5 \mathrm{ml}$ each of $0.2,0.4$, and $0.6 \mathrm{M}$ sucrose in $4 \mathrm{mM}$ HEPES-Tris ( $\mathrm{pH}$ 7.4) containing $0.1 \mathrm{mM}$ DTT. The sample $/ 0.2 \mathrm{M}$ sucrose layer including the interface between the $0.2 \mathrm{M}$ sucrose layer and the $0.4 \mathrm{M}$ sucrose layer (fraction $\mathrm{A}$ ), the $0.4 \mathrm{M}$ sucrose layer including the second interface (fraction $\mathrm{B}$ ), and the $0.4 \mathrm{M}$ sucrose layer including the third interface (fraction $\mathrm{C}$ ) were diluted 4- to 5-fold with $4 \mathrm{mM}$ HEPES-Tris ( $\mathrm{pH} 7.4$ ) containing $1 \mathrm{mM}$ DTT and centrifuged at $150,000 \times g_{\max }$ (Beckman $70 \mathrm{Ti}$ rotor) for $70 \mathrm{~min}$. The pellets were suspended in $4 \mathrm{mM}$ HEPES-Tris $(\mathrm{pH}$ 7.4) and analyzed for ATP-dependent Glu uptake. Fraction A exhibited the highest specific activity of ATP-dependent Glu uptake, and was used as the purified vesicle preparation.

\section{L-Glu Uptake into Synaptic Vesicles}

Vesicular Glu uptake was assayed by a modification of the method of Naito and Ueda $(7,8)$, as described previously by Kish and Ueda (27). Aliquots $(10 \mu \mathrm{g})$ of crude rat synaptic vesicles were incubated for $10 \mathrm{~min}$ at $30^{\circ} \mathrm{C}$ in a solution containing $20 \mathrm{mM}$ HEPES-KOH, pH 7.4, $0.25 \mathrm{mM}$ sucrose, $4 \mathrm{mM} \mathrm{MgSO}_{4}, 4 \mathrm{mM}$ $\mathrm{KCl}, 2 \mathrm{mM}$ L-aspartic acid, $50 \mu \mathrm{M}$ Glu, $2 \mathrm{mM}$ ATP, and $3.7 \times 10^{4} \mathrm{~Bq}\left[\mathrm{G}-{ }^{3} \mathrm{H}\right] \mathrm{Glu}(56 \mathrm{mmol} / \mathrm{Ci})$ (Amersham) in a final volume of $0.1 \mathrm{ml}$. Test compounds were dissolved in DMSO and added in $0.6 \mu \mathrm{l}$ aliquots to give final concentrations between $0.14 \mathrm{nM}$ and $25 \mu \mathrm{M}$. Synaptic vesicles were preincubated with test compounds for $30 \mathrm{~min}$ at $0^{\circ} \mathrm{C}$. Uptake was initiated by addition of a mixture of $2 \mathrm{mM}$ ATP and $50 \mu \mathrm{M}$ Glu (final concentration) containing $1 \mu \mathrm{Ci}$ of $\left[{ }^{3} \mathrm{H}\right] \mathrm{Glu}$. After $10 \mathrm{~min}$ at $30^{\circ} \mathrm{C}, 2.5 \mathrm{ml}$ of icecold $0.15 \mathrm{~m} \mathrm{KCl}$ were added and the mixture immediately filtered through Whatman $\mathrm{GF} / \mathrm{C}$ glass-fiber filter paper $(25 \mathrm{~mm})$ using a manifold under vacuum. The filters were washed 5 times with $2.5 \mathrm{ml}$ of $0.15 \mathrm{M} \mathrm{KCl}$ and placed in scintillation vials with scintillation cocktail (Cytoscint, ICN). The vials were shaken overnight and radioactivity determined in a Beckman LS 6500 scintillation spectrophotometer. Values obtained in the absence of ATP were subtracted from those in the presence of ATP to calculate ATPdependent uptake activity. The amount of radioactive Glu trapped on $\mathrm{GF} / \mathrm{C}$ glass-fiber filter paper was indistinguishable from that trapped on the Millipore HAWP filter (data not shown). Since the rate of filtration with $\mathrm{GF} / \mathrm{C}$ glass-fiber filter paper is greater, this type of filter was used in all experiments described here.

\section{Treatment of Data}

$\mathrm{IC}_{50}$ values for test compounds were determined from sigmoidal fit curves generated using the graphics software Origin ${ }^{\circledR}$ (Microcal Software, Inc.).

\section{RESULTS AND DISCUSSION}

Synaptic vesicles utilized in these studies were prepared by a modification of a previously pub- lished procedure (27); this method yields higher specific activity with a higher degree of ATPdependency, yet requires no sucrose density gradient ultracentrifugation. Frozen rat brains were thawed in isotonic sucrose, homogenized, and a P2 fraction prepared as previously described (27). The P2 synaptosomal pellet was washed with Krebs-Ringer buffer as opposed to isotonic sucrose prior to hypotonic osmotic shock with $6 \mathrm{mM}$ Tris-maleate, $\mathrm{pH}$ 8.1. Typically 5-7 $\mathrm{mg}$ of crude synaptic vesicles were obtainable from 35 rat brains, with ATPdependent Glu uptake of $1.5-3.0 \mathrm{nmol} / \mathrm{mg}$ protein after a $10 \mathrm{~min}$ incubation at $30^{\circ} \mathrm{C}$. The ratio of ATP-dependent to ATP independent Glu uptake is on the order of 35 to 100 . This modification results in a 1.2- to 2.4-fold increase in specific activity when compared to longer procedures utilizing bovine brain and sucrose density gradient centrifugation (27). The crude synaptic vesicles prepared in this manner were compared with sucrose density gradient-purified synaptic vesicles with respect to response to Rose Bengal lactone; preliminary experiments had indicated that the lactone form of Rose Bengal appeared slightly more potent than Rose Bengal. As shown in Fig. 1, both crude and purified vesicle preparations exhibited similar, if not identical, sensitivities to RBL. Hence, the modified crude vesicle preparation as described above was used in the rest of the experiments presented here.

\section{Structure-Activity Relationship}

Uptake of $\left[{ }^{3} \mathrm{H}\right] \mathrm{Glu}$ into synaptic vesicles $(10 \mu \mathrm{g})$ was measured in the presence of increasing concentrations of RBL during a 10-min incubation period at $30^{\circ} \mathrm{C}$. Vesicular uptake of $\left[{ }^{3} \mathrm{H}\right] \mathrm{Glu}$ is plotted as a function of inhibitor concentration. Figure 2 shows an apparent sigmoidal dose-response curve for inhibition of $\left[{ }^{3} \mathrm{H}\right] \mathrm{Glu}$ uptake by RBL. The concentration of RBL required to inhibit vesicular Glu uptake by $50 \%\left(\mathrm{IC}_{50}\right)$ was $18 \mathrm{nM}$. For comparison, a dose-response curve for tetraiodosuccinyl fluorescein, a less potent compound, was included.

Rose Bengal is a polyhalogenated derivative of the fluorescent dye fluorescein. It consists of a polyiodinated xanthene moiety and a polychlorinated benzoate moiety. Fluorescein by itself is ineffective in inhibiting vesicular Glu uptake (24).

To determine the structural features of RBL that account for potent inhibition of vesicular Glu uptake, we determined the $\mathrm{IC}_{50}$ values for 18 other fluorescein-related dyes structurally similar to Rose Bengal. 

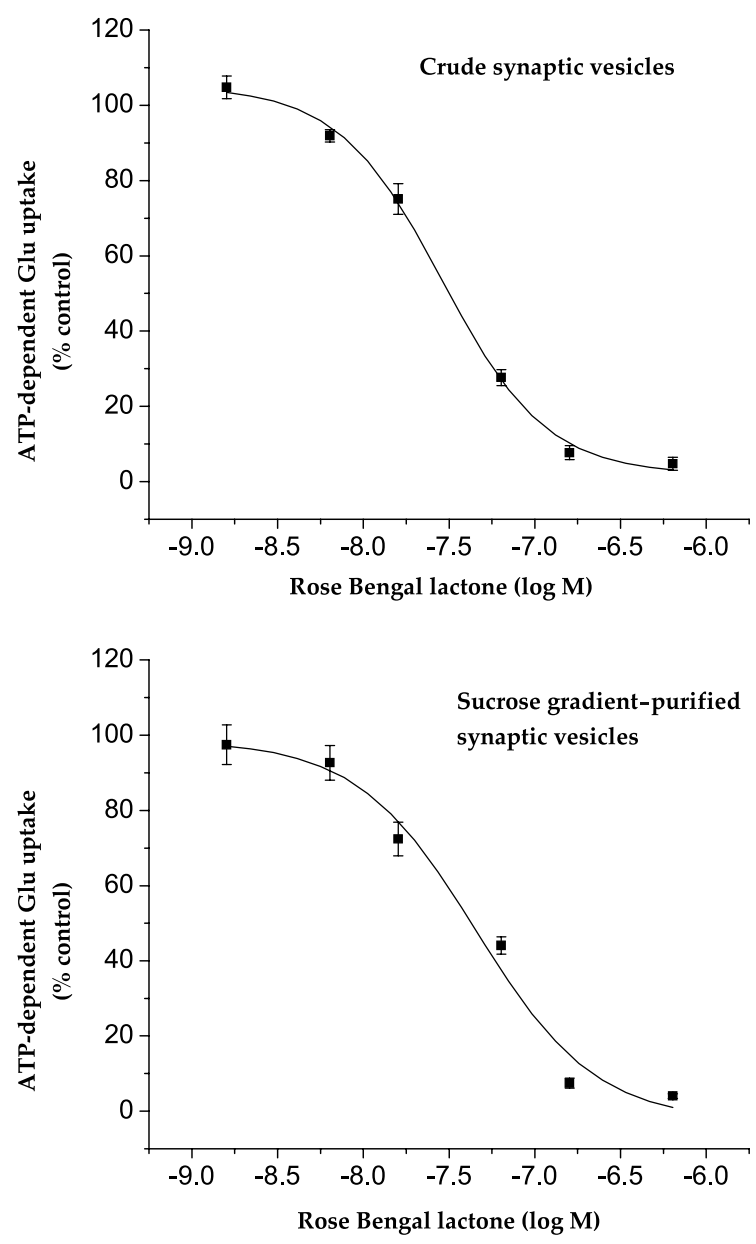

Fig. 1. Crude and sucrose density gradient-purified synaptic vesicles have similar sensitivities to Rose Bengal lactone. Crude (top) or purified (bottom) synaptic vesicle preparations $(10 \mu \mathrm{g}$ of protein each) were subjected to ATP-dependent Glu uptake assay in the presence of various concentrations of Rose Bengal lactone (RBL), as described in 'Experimental Procedure.' The control values (100\%) for vesicular Glu uptake were $1.53 \mathrm{nmol} \mathrm{mg} \mathrm{mg}^{-1} 10 \mathrm{~min}^{-1}$ with crude synaptic vesicles and $1.90 \mathrm{nmol} \mathrm{mg}^{-1} 10 \mathrm{~min}^{-1}$ with sucrose-gradient purified synaptic vesicles.

Sigmoidal dose-response curves were generated for all compounds listed in Table I. The compounds are listed in order of potency as judged by $\mathrm{IC}_{50}$ value for inhibition of vesicular Glu uptake. The data in Table I were obtained with vesicles pooled from multiple preparations of 35 brains each.

Upon comparison of the $\mathrm{IC}_{50}$ values of various fluorescein derivatives in Table I, structural features responsible for inhibition of vesicular Glu uptake have become apparent. Conversion of the carboxyl group of Rose Bengal to the lactone form (RBL) does not significantly alter potency. Rose Bengal was found to have an $\mathrm{IC}_{50}$ of $22 \mathrm{nM}$ and $\mathrm{RBL}$ an $\mathrm{IC}_{50}$ of $18 \mathrm{nM}$.

This minor difference in $\mathrm{IC}_{50}$ between Rose Bengal and RBL indicates that the presence of an acidic carboxyl group hardly affects potency. However, conversion of the carboxyl group of Rose Bengal to either the methyl ester $\left(\mathrm{IC}_{50}, 44 \mathrm{nM}\right)$ or benzyl ester $\left(\mathrm{IC}_{50}, 65 \mathrm{nM}\right)$ resulted in 2- and 3-fold increases in $\mathrm{IC}_{50}$, respectively. Complete removal of the carboxyl residue of Rose Bengal resulted in an $\mathrm{IC}_{50}$ value of $68 \mathrm{nM}$.

Erythrosin B and Erythrosin B lactone have similar structures to Rose Bengal and RBL, respectively, but differ in that erythrosins lack the chloride residues on the benzoate moiety. Erythrosin B and Erythrosin B lactone were also found to be potent inhibitors, with similar $\mathrm{IC}_{50}$ values of 35 and $30 \mathrm{nM}$, respectively. Thus, the presence or absence of chloride and perhaps other halogens on the benzoate moiety does not greatly affect potency. However, the addition of a thiocyanate residue on the benzoate moiety of Erythrosin B lactone does result in significant reduction of potency, increasing the $\mathrm{IC}_{50}$ to $690 \mathrm{nM}$. This 23 -fold reduction in potency could be due to the size of the thiocyanate group, which is much larger than a single chloride residue. Removal of the phenyl group from Erythrosin B markedly reduces potency to micromolar concentrations, as evident in tetraiodosuccinylfluorescein. Thus, the phenyl group appears to substantially contribute to potency.

Phloxine B differs from Rose Bengal in that it contains bromine rather than iodine residues on the xanthene moiety. Phloxine B was also found to be a potent inhibitor of vesicular Glu uptake, with an $\mathrm{IC}_{50}$ value of $51 \mathrm{nM}$. However, removal of bromine residues from the xanthene moiety resulted in substantial decrease in potency, as seen in tetrachlorofluorescein $\left(\mathrm{IC}_{50}, 15 \mu \mathrm{M}\right)$. Thus, halogenation of the xanthene moiety appears crucial for potent inhibition of ATPdependent Glu uptake.

For Phloxine B, in contrast to Rose Bengal, the presence of chlorine residues on the benzoate moiety appears to be required for high potency. Eosin Y lacks halogens on the benzoate moiety and exhibited a much lower potency $\left(\mathrm{IC}_{50}, 740 \mathrm{nM}\right)$ than Phloxine B. However, if the benzoate is converted to either the methyl or ethyl ester, the potency greatly increases; their $\mathrm{IC}_{50}$ values are decreased to 120 and $65 \mathrm{nM}$, respectively. Eosin Y lactone was twice as potent as Eosin Y. 


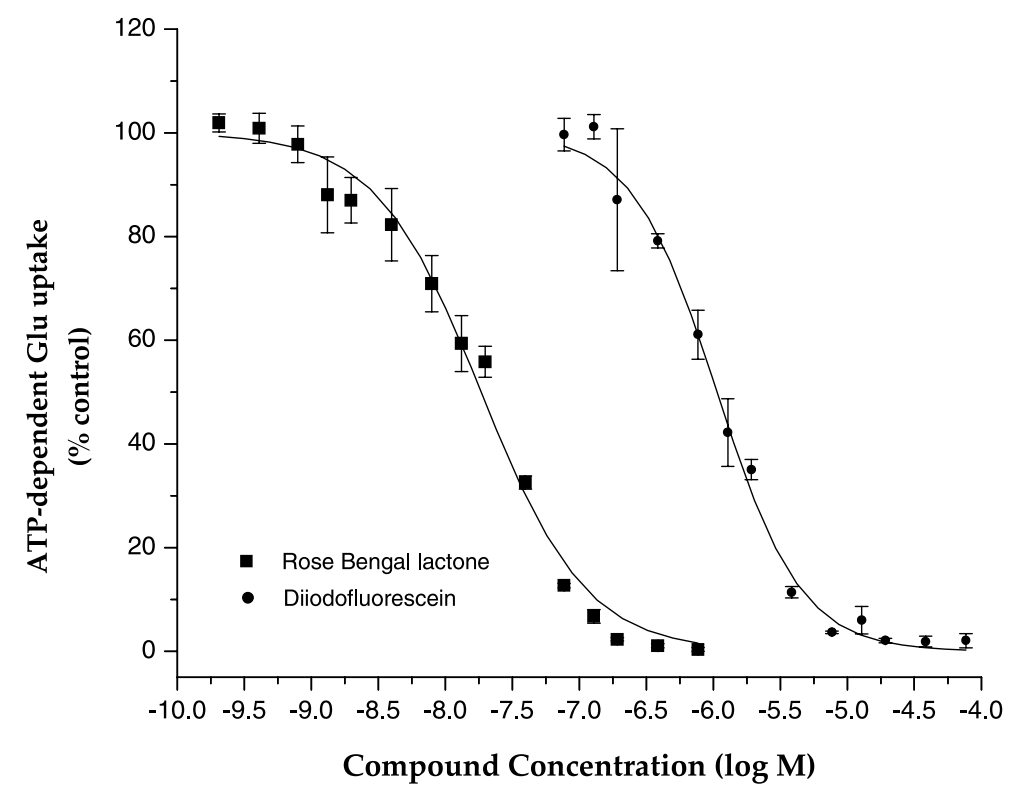

Fig. 2. Effect of RBL and diiodofluorescein on ATP-dependent uptake of $\left[{ }^{3} \mathrm{H}\right] \mathrm{Glu}$ into synaptic vesicles. Rat brain synaptic vesicles $(10 \mu \mathrm{g})$ were incubated in the absence or presence of various concentrations of test agents (final concentration) for 30 min at $0^{\circ} \mathrm{C}$, then assayed for ATP-dependent uptake for $10 \mathrm{~min}$ at $30^{\circ} \mathrm{C}$, as described in 'Experimental Procedure.' Uptake in the presence of carrier (0.6\% DMSO) alone was determined to be $2.90 \mathrm{nmol} \mathrm{mg} \mathrm{mg}^{-1} 10 \mathrm{~min}^{-1}$. Data points represent the mean \pm standard deviation $(n=3)$.

Erythrosin B lactone contains four iodine residues on the xanthene moiety and has an $\mathrm{IC}_{50}$ of $30 \mathrm{nM}$. Interestingly, tetrachlorofluorescein, which lacks halogens on the xanthene moiety, was found to be far less potent $\left(\mathrm{IC}_{50}, 15 \mu \mathrm{M}\right)$. Moreover, fluorescein derivatives bearing two halogen residues on the xanthene moiety, such as diiodofluorescein lactone $\left(\mathrm{IC}_{50}, 1.1 \mu \mathrm{M}\right)$ and $2^{\prime}, 7^{\prime}$-dichlorofluorescein lactone $\left(\mathrm{IC}_{50}>64 \mu \mathrm{M}\right)$, showed substantially reduced potency. Pyrogallol, which bears $4^{\prime}, 5^{\prime}$-dihydroxyl groups instead of $4^{\prime}, 5^{\prime}$-diiodo groups, was also quite ineffective $\left(\mathrm{IC}_{50}>32 \mu \mathrm{M}\right)$. These data demonstrate the critical importance of having more than two halogens, iodine in particular, on the xanthene moiety.

Replacement of two bromine residues on Eosin $\mathrm{Y}$ lactone with nitro groups results in higher $\mathrm{IC}_{50}$ values. Thus, Eosin B lactone was approximately 6fold less potent than Eosin $\mathrm{Y}$ lactone. The lactone form of Eosin B was twice as potent as its non-lactone form, similar to the case of Eosin Y lactone, as mentioned above.

Finally, we have examined whether the oxygen atom linking the two benzene rings of xanthene is required for generating high potency. To this end, we have tested $3^{\prime}, 3^{\prime \prime}, 5^{\prime}, 5^{\prime \prime}$-tetraiodophenolphthalein (which differs from Erythrosin B only in lacking that particular oxygen atom) for the ability to inhibit vesicular Glu uptake. The $\mathrm{IC}_{50}$ value was determined to be $3.9 \mu \mathrm{M}$, indicating a substantial reduction in potency and hence a critical role of that oxygen atom in creating a highly potent ligand.

We have shown that Rose Bengal, Erythrosin B, and their lactone forms are the most potent inhibitors of the vesicular Glu uptake system of all the fluorescein derivatives tested here. Comparison of $\mathrm{IC}_{50}$ values for different halogenated derivatives of fluorescein (Table I) has revealed that potency is dependent on three key structural features. Polyhalogens on the xanthene moiety seem to be most important. Iodine residues on the xanthene moiety yield higher potency than do bromine residues, as evident from Erythrosin $\mathrm{B}\left(\mathrm{IC}_{50}, 35 \mathrm{nM}\right)$ being a superior inhibitor to Eosin Y ( $\left.\mathrm{IC}_{50}, 740 \mathrm{nM}\right)$. The phenyl group linked to the xanthene moiety is also essential for high potency. 2,4,5,7-tetraiodosuccinylfluorescein ( $\mathrm{IC}_{50}$, $2.2 \mu \mathrm{M})$ devoid of the phenyl group is a far less effective inhibitor than Erythrosin B lactone $\left(\mathrm{IC}_{50}\right.$, $30 \mathrm{nM}$ ). On the other hand, the carboxyl group attached to the phenyl group contributes little to the potency. Of further interest is the observation indicating that the oxygen atom linking the two benzene rings of xanthene is crucial in conferring high inhibition potency on Rose Bengal, Erythrosin B, and their lactone forms. Without this oxygen atom, the structural rigidity of these compounds would be lost. 
The two benzene rings would not be maintained on the same plane, but would most likely be perpendicular to each other. Thus, $2^{\prime}-, 5^{\prime}-, 6^{\prime}-$, and $7^{\prime}$-iodine atoms would not be on the same plane. These observations indicate that simply attaching bulky groups such as iodine to the xanthene moiety is not sufficient to create high potency; these groups would have to assume a specific orientation toward each other. This suggests that the potent inhibitory effect is produced not through simple lipophilic interaction with membrane lipids, but through a specific interaction with a protein or a common motif of certain proteins. Thus, to convert fluorescein (an ineffective agent) to a potent inhibitor would require attachment of more than two bulkier halogen groups and a hydrophobic group, such as the phenyl group, to the xanthene moiety. The importance of the oxygen atom connecting the two benzene rings is to be emphasized.

RBL, Rose Bengal, Erythrosin B, and Phloxine $\mathrm{B}$ are likely to elicit the inhibitory effect on vesicular Glu uptake via the same mechanism. The mechanism of the inhibitory action is, however, not known. The inhibitory effect of Rose Bengal is not due to any of the following: (a) inhibition of ATP hydrolysis or membrane potential formation, (b) blockade of Glu binding to the transporter, (c) dissipation of membrane potential, and (d) enhancing Glu efflux (24). It has also been shown that Rose Bengal can inhibit $\mathrm{Na}^{+}$-dependent Glu uptake into synaptosomes, but only at substantially higher concentrations $\left(\mathrm{IC}_{50}=2 \mu \mathrm{M}\right)$. Similar results were obtained with $\mathrm{RBL} \quad\left(\mathrm{IC}_{50}=0.7 \mu \mathrm{M}\right.$ for Glu uptake and $\mathrm{IC}_{50}=1.2 \mu \mathrm{M}$ for GABA uptake). These observations are in accord with the studies by Logan and Swanson (28) using brain homogenates, which have shown that Erythrosin B inhibits neurotransmitter accumulation with an $\mathrm{IC}_{50}$ of approximately $1 \mu \mathrm{M}$. We have also observed that RBL inhibits other electrochemical proton gradient-driven uptake systems, namely GABA and serotonin vesicular uptake systems, with potencies $\left(\mathrm{IC}_{50}=35 \pm 5.8 \mathrm{nM}\right.$ for GABA uptake and $38 \pm 13 \mathrm{nM}$ for serotonin uptake) comparable to the potency for vesicular Glu uptake. These observations indicate that electrochemical proton gradient-driven vesicular uptake systems are far more sensitive to Rose Bengal, Erythrosin B, and their lactone forms than are $\mathrm{Na}^{+}$. gradient-driven plasma membrane uptake systems. Although the inhibitory effect on $\mathrm{Na}^{+}$-dependent plasma membrane uptake could be due to perturbation of membranes through interaction with lipids, as suggested by Logan and Swanson (28), the far more potent inhibitory effects observed on electrochemical proton gradient-dependent uptake systems, together with the stringent requirement for a particular 3-dimensional structure of Rose Bengal, Erythrosin $\mathrm{B}$, and their lactone forms, may indicate that inhibition is occurring through interaction with a protein component. Based upon the observations mentioned above, we suggest that RBL, as well as related compounds such as Rose Bengal, Erythrosin B, and Phloxine B, may block, with high potency, the electrochemical proton gradient-induced conformational change of the vesicular transporter or proton efflux, both necessary for transmitter transport to occur $(9,10,15,29,30)$.

In conclusion, multiple bulkier halogens and the phenyl group (but not the alkyl group) attached to the xanthene moiety, as well as the xanthene's oxygen bridging, constitute the pharmacophore of Rose Bengal and account for its potent inhibitory effect on vesicular Glu uptake.

\section{ACKNOWLEDGMENTS}

This work was supported by Grant NS 42200 from the National Institutes of Health. We thank Dr. Francisco Amat-Guerri, Consejo Superior de Investigaciones Cientificas, Instituto de Quimica Organica General, Madrid, Spain, for kindly providing some of the fluorescein analogs; Kiyokazu Ogita and Koji Hirata for carrying out part of an initial experiment; and Mary Roth for excellent assistance in preparation of the manuscript.

\section{REFERENCES}

1. Ueda, T. 1986. Glutamate transport in the synaptic vesicle. Pages 173-195 in Roberts, P. J. and Storm-Mathisen Bradford, J. H. F. (eds.), Excitatory amino acids. London: Macmillan.

2. Nicholls, D. G. 1989. Release of Glutamate aspartate, and $\gamma$-aminobutyric acid from isolated nerve terminals. J. Neurochem. 52:331-341.

3. Maycox, P. R. and Hell Jahn, J. W. R. 1990. Amino acid neurotransmission: Spotlight on synaptic vesicles. Trends Pharmacol. Sci. 13:83-87.

4. Özkan, E. D. and Ueda, T. 1998. Glutamate transport and storage in synaptic vesicles. Jpn. J. Pharmacol. 77:1-10.

5. Reimer, R. J. Fremeau, R. T. Jr. and Bellocchio Edwards, E. E. R. H. 2001. The essence of excitation. Curr. Opin. Cell Biol. 13:417-421.

6. Otis, T. S. 2001. Vesicular glutamate transporters incognito. Neuron 29:11-14.

7. Naito, S. and Ueda, T. 1983. Adenosine triphosphate-dependent uptake of glutamate into Protein I-associated synaptic vesicles. J. Biol. Chem. 258:696-699. 
8. Naito, S. and Ueda, T. 1985. Characterization of glutamate uptake into synaptic vesicles. J. Neurochem. 44:99-109.

9. Tabb, J. S. Kish, P. E. Van Dyke, R. and Ueda, T. 1992. Glutamate transport into synaptic vesicles: Roles of membrane potential $\mathrm{pH}$ gradient, and intravesicular $\mathrm{pH}$. J. Biol. Chem. 267:15412-15418.

10. Bellocchio, E. E. Reimer, R. J. Fremeau, R. T. Jr. and Edwards, R.H. 2000. Uptake of glutamate into synaptic vesicles by an inorganic phosphate transporter. Science 289:957-960.

11. Takamori, S. Rhee, J. S. Rosenmund, C. and Jahn, R. 2000. Identification of a vesicular glutamate transporter that defines a glutamatergic phenotype in neurons. Nature 407:189-194.

12. Fremeau, R. T. Jr. Voglmaier, S. Seal, R. P. and Edwards, R. H. 2004. VGLUTs define subsets of excitatory neurons and suggest novel roles for glutamate. Trends Pharmacol. Sci. 27:98-103.

13. Maycox, P. R. Deckwerth, T. Hell, J. W. and Jahn, R. 1988. Glutamate uptake by brain synaptic vesicles. J. Biol. Chem. 263:15423-15428.

14. Fykse, E.M. and Christensen Fonnum, H. F. 1989. Comparison of the properties of $\gamma$-aminobutyric acid and L-glutamate uptake into synaptic vesicles isolated from rat brain. J. Neurochem. 52:946-951.

15. Wolosker, H. de Souza, D. O. and de Meis, L. 1996. Regulation of glutamate transport into synaptic vesicles by chloride and proton gradient. J. Biol. Chem. 271:11726-11731.

16. Carlson, M. D. and Kish Ueda, P. E. T. 1989. Glutamate uptake into synaptic vesicles: Competitive inhibition by bromocriptine. J. Neurochem. 53:1889-1894.

17. Moriyama, Y. Amakatsu, K. Yamada, H. and Park Futai, M. Y. M. 1991. Inhibition of neurotransmitter and hormone transport into secretory vesicles by 2-(4-phenylpiperidino) cyclohexanol and 2-bromo- $\alpha$-ergocryptine: Both compounds act as uncouplers and dissipate the electrochemical gradient of protons. Arch. Biochem. Biophys. 290:233-238.

18. Winter, H. C. and Ueda, T. 1993. Glutamate uptake system in the presynaptic vesicle: Glutamic acid analogs as inhibitors and alternate substrates. Neurochem. Res. 18:79-85.

19. Moriyama, Y. and Yamamoto, A. 1995. Vesicular L-glutamate transporter in microvesicles from bovine pineal glands: Driving force mechanism of chloride anion activation, and substrate specificity. J. Biol. Chem. 270:22314-22320.
20. Roseth, S. Fykse, E. M. and Fonnum, F. 1995. Uptake of Lglutamate into rat brain synaptic vesicles: Effect of inhibitors that bind specifically to the glutamate transporter. J. Neurochem. 65:96-103.

21. Özkan, E. D. and Lee Ueda, F. S. T. 1997. A protein factor that inhibits ATP-dependent glutamate and $\gamma$-aminobutyric acid accumulation into synaptic vesicles: Purification and initial characterization. Proc. Natl. Acad. Sci. USA 94:41374142.

22. Carrigan, C. N. Esslinger, C. S. Bartlett, R. D. Bridges, R. J. and Thompson, C. M. 1999. Quinoline-24-dicarboxylate acids: Synthesis and evaluation as inhibitors of the glutamate vesicular transport system. Bioorg. Med. Chem. Lett. 9:2607-2712.

23. Carrigan, C. N. and Bartlett, R. D. 2002. Synthesis and in vitro pharmacology of substituted quinoline-24-dicarboxylic acids as inhibitors of vesicular glutamate transport. J. Med. Chem. 45:2260-2270.

24. Ogita, K. Hirata, K. Bole, D. G. Yoshida, S. Tamura, Y. and Leckenby Ueda, A. M. T. 2001. Inhibition of vesicular glutamate storage and exocytotic release by Rose Bengal. J. Neurochem. 77:34-42.

25. Martinez-Utrilla, R. Martin, M. E. Amat-Guerri, F. and Sastre Botija, R. J. M. 1988. New halogenated succinylfluorescein dyes. Synthesis and evaluation as singlet oxygen photosensitizers of their free and polymer-bound forms. Dyes Pigments 10:47-61.

26. Amat-Guerri, F. Lopez-Gonzalez, M. M. C. and MartinezUtrilla Sastre, R. 1990. Synthesis and spectroscopic properties of New Rose Bengal and Eosin Y derivatives. Dyes Pigments 12:249-272.

27. Kish, T. and Ueda, P. E. 1989. Glutamate accumulation into synaptic vesicles. Meth. Enzymol. 174:9-25.

28. Logan, W. L. and Swanson, J. M. 1979. Erythrosin B inhibition of neurotransmitter accumulation by rat brain homogenate. Science 206:363-364.

29. Njus, D. and Kelley Harnadek, P.M. G.J. 1986. Bioenergetics of secretory vesicles. Biochim. Biophys. Acta 853:237-265.

30. Shioi Ueda, J. T. 1990. Artificially imposed electrical potentials drive L-glutamate uptake into synaptic vesicles of bovine cerebral cortex. Biochem. J. 267:63-68. 